\title{
EPIDEMIOLOGICAL AND CLINICAL SPECTRUM OF DENGUE FEVER AT TERTIARY CARE HOSPITAL IN CHITWAN: A HOSPITAL BASED STUDY
}

\author{
Bidhan Shrestha ${ }^{1, *}$, Rakshya Shrestha² $^{2}$, Arun Sedhain ${ }^{3}$, Sabita Shrestha ${ }^{4}$, Bishnu Mani Dhital ${ }^{5}$, Suresh Shrestha ${ }^{1}$, Rituraj Tiwari $^{1}$ \\ ${ }^{1}$ Department of Medicine, Chitwan Medical College, Bharatpur, Chitwan, Nepal \\ ${ }^{2}$ Department of Medical Oncology, Institute of Medicine, Kathmandu, Nepal \\ ${ }^{3}$ Nephrology Unit, Department of Medicine, Chitwan Medical College, Bharatpur, Chitwan, Nepal \\ ${ }^{4}$ Department of Obstetrics and Gynaecology, Chitwan Medical College, Bharatpur, Chitwan, Nepal \\ ${ }^{5}$ Cardiology Unit, Department of Medicine,Chitwan Medical College, Bharatpur, Chitwan, Nepal
}

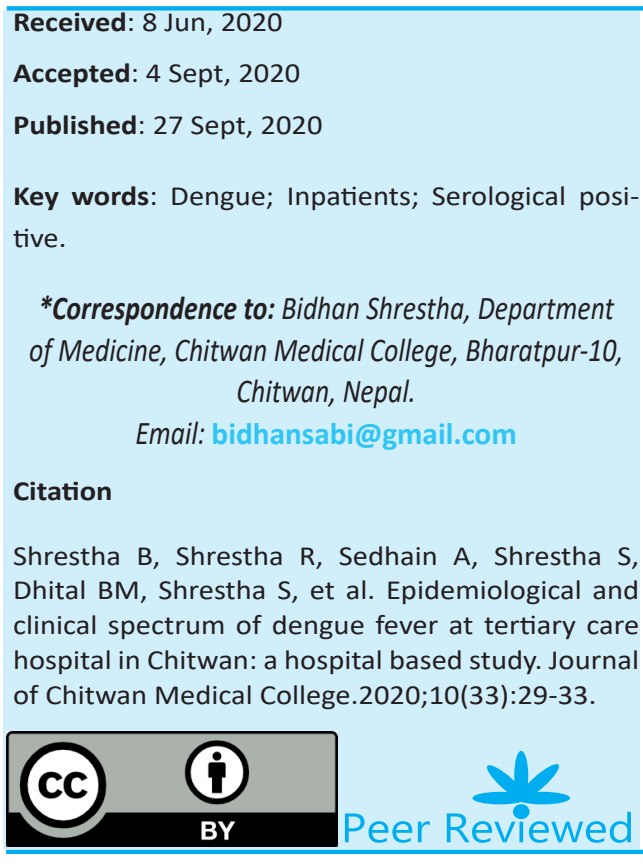

INTRODUCTION

Dengue fever is a dreadful disease caused by the Dengue virus. Dengue virus is an RNA virus, a member of flaviviradae family with 4 different serotypes (DENV1-4). It is transmitted to humans by a bite of a female mosquito called Aedes (Ochlerotatus) aegypti. It has an incubation period of 4-10 days.

In the late $18^{\text {th }}$ century, Benjamin Rush termed dengue as "Break Bone Fever". In 2001, there was a global epidemic and by the year 2010, it was one of the 17 neglected tropical diseases.

WHO estimates more than 50 to 100 million infections worldwide every year. ${ }^{3}$ In Nepal, dengue was first identified in a Japanese traveler in 2004. The first case of dengue in Nepali population was reported in 2006 with an outbreak in 9 districts in the same year. Other massive outbreaks took place in 2006, 2010, 2013, 2016 and 2019.

The aim was to study the epidemiological and clinical spectrum of dengue fever admitted in tertiary care center of Central Nepal, hence our effort is to improve the diagnostic facilities and preventive measures and alert the citizens against this disease.

\section{METHODS}

This prospective study was carried out in Chitwan Medical College (CMC), Bharatpur, Chitwan from $1^{\text {st }}$ of September 2019 to $30^{\text {th }}$ of February 2020. Chitwan Medical College (CMC), being a tertiary multidisciplinary hospital, people of undiagnosed fever come from various nearby districts. The approval for the research was taken from the Ethical Review Committee of CMC. After taking informed consent, a prospective consecutive study was carried out during this six-month period. All the patients admitted in tropical ward with diagnosis of dengue fever was included during the study period.

Inclusion criteria were patients above 18 years of age, who had fever with either Dengue NS1 antigen test, IgM or IgG ELISA test positive. Exclusion criteria were age below 18 years or any coinfection with tropical diseases like Scrub typhus, Malaria, Leptospirosis, Enteric fever or other bacterial infections.

Detailed history, clinical examinations were performed in these patients. Laboratory investigations such as complete Blood count, liver function tests and ultrasound abdomen was done. Dengue NS1 test was done to those who had fever for less than 5 days, Immunoglobulin M (IgM), Immunoglobulin G 
(IgG) ELISA was done in patients having fever for more than 7 days and both antigen test and ELISA was done who had fever between 5 and 7 days. These patients were categorized as Dengue fever, Dengue hemorrhagic fever and Dengue Shock syndrome and managed according to the WHO protocol.

Laboratory investigations such as complete blood count and liver function tests were done at the time of admission, during hospital stay and a day before discharge to look for the improvements in leucocytes, platelet counts and transaminases level. Patients were followed up in OPD after 1 week of discharge. Data were collected by using a predesigned proforma and entered in a SPSS 16.0 (Statistical Package for Social science) version. Demographic, clinical, hematological, biochemical, and radiological parameters were assessed. Mean and standard deviation was calculated for continuous variables and frequencies for categorical variables.

\section{RESULTS}

In our study, a total of 241 patients admitted were diagnosed with dengue fever during the six months period. The age and sex distribution of the patients is depicted in Table 1. The mean age of the patients was calculated as 34.44 years on the basis of descriptive statistics. More than half $(56 \%)$ of the dengue patients belonged to the age group of 25-44 years. Dengue was more commonly seen in male than in females (61.4\% Vs $38.6 \%$ ) with male: female ratio of 1.6:1.

Table 1: Age and sex distribution of dengue cases

$(n=241)$

\begin{tabular}{|l|c|c|c|}
\hline \multirow{2}{*}{ Age Group (in years) } & \multicolumn{2}{|c|}{ Sex } & \multirow{2}{*}{ Total (\%) } \\
\cline { 2 - 4 } & Male (\%) & Female (\%) & (23.23) \\
\hline $15-24$ & 34 & 22 & $56(23.85)$ \\
\hline $25-34$ & 52 & 32 & $84(34.85)$ \\
\hline $35-44$ & 31 & 21 & $52(21.57)$ \\
\hline $45-54$ & 18 & 10 & $28(11.61)$ \\
\hline $55-64$ & 7 & 5 & $12(4.97)$ \\
\hline$>/=65$ & 6 & 3 & $09(3.73)$ \\
\hline Total & $148(61.4)$ & $93(38.6)$ & $241(100)$ \\
\hline
\end{tabular}

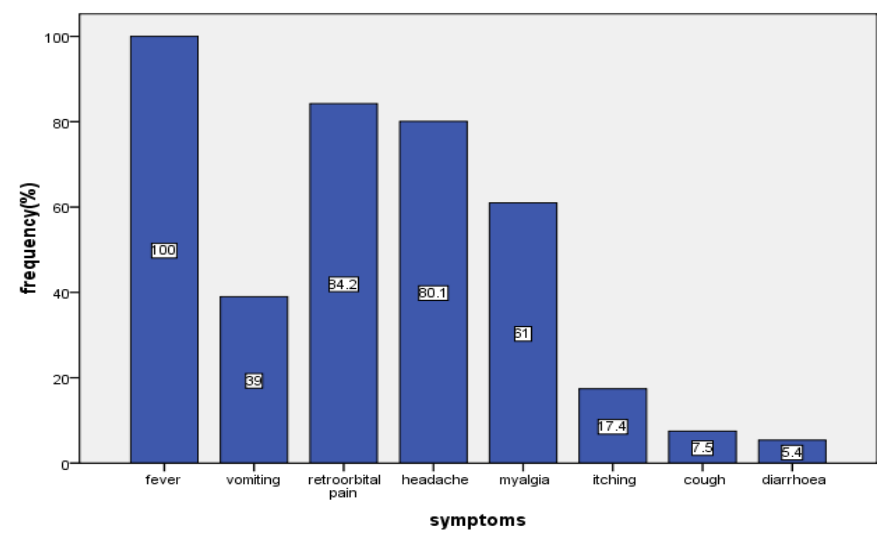

Figure 1: Distribution of dengue cases according to symptoms

As the clinical features are concerned, all the patients had come with fever with one or more associated symptoms as shown in
Figure 1 below. The mean duration of the fever was 3.58 days. Another common complaint in our study was retro-orbital pain present in 203 patients (84.2\%) followed by headache $(80.1 \%)$, myalgia (61\%) and vomiting (39\%).

Table 2 showed most patients being admitted were from Chitwan district (68.46\%), followed by Makwanpur (13.27\%) and Nawalparasi district (10.37\%).

\section{Table 2: District wise distribution of dengue cases}

\begin{tabular}{|l|c|}
\hline Districts & Frequency (\%) \\
\hline Chitwan & $165(68.46)$ \\
\hline Makwanpur & $32(13.27)$ \\
\hline Nawalparasi & $25(10.37)$ \\
\hline Gorkha & $05(2.07)$ \\
\hline Butwal & $03(1.24)$ \\
\hline Bara & $05(2.07)$ \\
\hline Tanahun & $04(1.65)$ \\
\hline Dang & $01(0.41)$ \\
\hline Dhading & $01(0.41)$ \\
\hline Total & $241(100)$ \\
\hline
\end{tabular}

Table 3 showed the laboratory parameters of the patients The most common hematological abnormality was leucopenia (71.8\%).

Table 3: Abnormal laboratory parameters of dengue cases

\begin{tabular}{|c|c|c|}
\hline \multicolumn{2}{|c|}{ Laboratory Parameters } & $\begin{array}{l}\text { Frequency } \\
\text { (\%) }\end{array}$ \\
\hline \multicolumn{2}{|c|}{ Leucopenia (<4000 cmm) } & $173(71.8)$ \\
\hline \multicolumn{2}{|c|}{ Leucocytosis (>11000 cmm) } & $3(1.2)$ \\
\hline \multirow{3}{*}{$\begin{array}{l}\text { Thrombocytopenia } \\
\left(\mathrm{mm}^{3}\right)\end{array}$} & $1,00,000-1,50,000$ & $129(53.5)$ \\
\hline & $50,000-1,00,000$ & $91(37.8)$ \\
\hline & $<50,000$ & $21(8.7)$ \\
\hline \multicolumn{2}{|l|}{ AST(>37 IU/L) } & $116(48.1)$ \\
\hline \multicolumn{2}{|l|}{$\operatorname{ALT}(>42 \mathrm{IU} / \mathrm{L})$} & $110(45.6)$ \\
\hline
\end{tabular}

Table 4: Patient distribution according to days of fever

\begin{tabular}{|l|c|}
\hline Days of Fever & Number of patients (\%) \\
\hline 1 & $3(1.2)$ \\
\hline 2 & $36(14.9)$ \\
\hline 3 & $88(36.5)$ \\
\hline 4 & $21(8.7)$ \\
\hline 5 & $52(21.6)$ \\
\hline 6 & $39(16.2)$ \\
\hline 7 & $2(0.8)$ \\
\hline Total & $241(100)$ \\
\hline
\end{tabular}

The Table 4 showed the days when patients presented to the hospital with fever. More than $60 \%$ of patient presented be- 
fore fifth day of onset of fever so as per protocol these patients were tested for NS1 antigen only. From 5 to $7^{\text {th }}$ day around $39 \%$ of patients presented with fever. None presented after $7^{\text {th }}$ day. This corrugates well with the positivity of serological test done depending on the days of duration of fever. Serological profile of the patient is depicted below in Figure 2 .

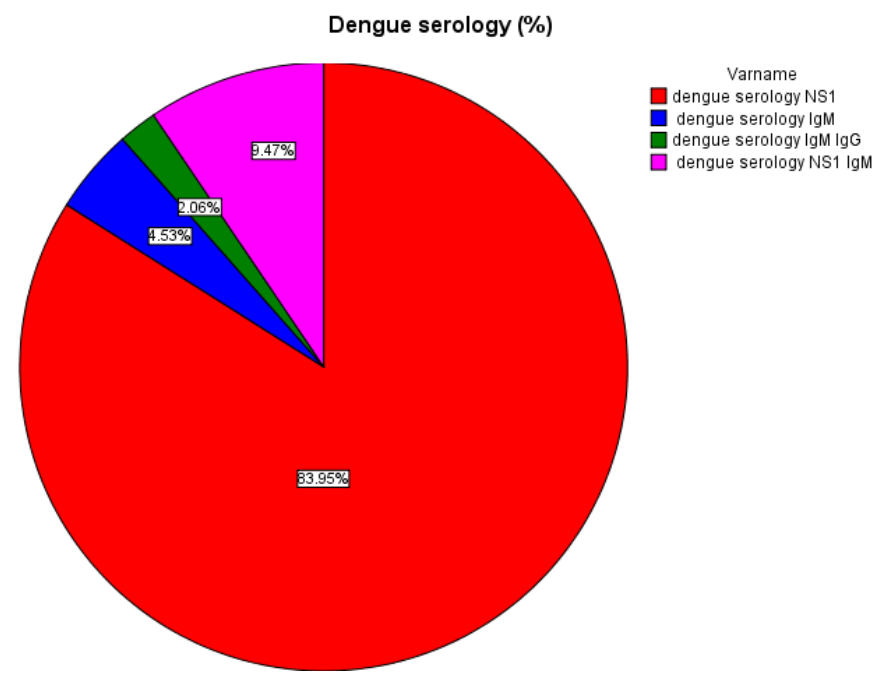

Figure 2: Serological Profile of Dengue Fever Patients

The most common type of serology which was positive was NS1 Antigen test (84\%). 23 patients (9.5\%) were positive for both NS1 and IgM antibody.

Table 5: USG Findings in Dengue

\begin{tabular}{|l|c|}
\hline USG findings & No of patients (\%) \\
\hline Ascites & $1(0.4)$ \\
\hline GB Edema & $37(15.4)$ \\
\hline Hepatomegaly & $35(14.5)$ \\
\hline Normal & $168(69.7)$ \\
\hline Total & $241(100.0)$ \\
\hline
\end{tabular}

The Ultrasonographic (USG) findings, out of the total 241 patients, most of them(69.7\%) had normal USG findings. Gall bladder edema was seen in 37 (15.4\%) patients, 35(14.5\%) had hepatomegaly and only one patient had ascites. The details of USG findings according to the positive serological tests is shown below in Table 6.

Table 6: USG Findings on the basis of positive serology

\begin{tabular}{|l|c|c|c|c|c|}
\hline USG & NS1 & IgM & IgG & IgG+IgM & NS1+IgM \\
\hline Ascites & 1 & 0 & 1 & 0 & 0 \\
\hline GB Edema & 14 & 7 & 37 & 2 & 13 \\
\hline Hepatomegaly & 26 & 2 & 35 & 0 & 5 \\
\hline
\end{tabular}

Out of 241 patients, most of them recovered and were discharged. Only one patient died.

\section{DISCUSSION}

During the study period of six months, 241 febrile patients diagnosed with dengue fever were admitted in the ward. Age of the patients ranged from 18 to 72 years. The most affected age group was $25-44$ years (56\%). These findings are similar to the study conducted by Mehta et al. and Deshwal et al. This age group being, a productive phase with a high male preponderance, work outside their houses and are more susceptible to mosquito bites. However, a study done in Kolkata had majority of cases between 11 to 30 years.

Out of total admitted 148 patients (62\%) were male and 93 $(38 \%)$ were female with the ratio of 1.6:1 respectively. Similar results were observed in studies by Chitkara et al , Chrispal et al. and Ittyachen et al. A study done by Chaterjee et al. showed equal sex distribution whereas a South American study showed more infection in females than males.

Around $68 \%$ of patients with dengue fever were from Chitwan followed by neighboring districts such as Makwanpur, Nawalparasi, Gorkha, Butwal, Bara and Tanahu respectively which imply that this virus is not limited to terai regions only. This may be due to travel to an endemic area, urbanization and prevalence of marshy areas where mosquitoes breed and multiply easily. ${ }^{5}$

The mean duration of hospital stay in our study was 3.86 days conflicting with the study done by Mehta et al. ${ }^{10}$ This could be because of non-availability of beds in our hospital during the outbreak of dengue fever and early improvement of patients leading to early discharge of the patients.

The mean duration of fever was 3.58 days. However a research conducted in Sri Lanka by Kularatne et al.3 and in North India by Awasthi et al. showed a mean duration of fever of 7 and 10 days respectively. In this study all the patients had fever with less than $20 \%$ accounting for itching, cough and diarrhea. These findings are comparable to the study done by Nepal et al. In contrast the studies by Jayadas et al and Pande et al found vomiting and a study in Kerala showed gastrointestinal symptoms as the most common symptoms.

Leucopenia in 173 patients(72\%) was the most common laboratory finding consistent with studies performed by Karoli et al. and Singh $\mathrm{N}$ et al. A study by Dhivya et al. showed leucopenia in only $36 \%$ of study population, lesser than as compared to our study. Leucopenia was most commonly observed because of the direct suppression of bone marrow by the virus. ${ }^{20}$

Thrombocytopenia was most commonly seen in studies conducted by Jayadas, et al. ${ }^{20}$, Kumar et al . and Laul et al. However in this present study thrombocytopenia was the second most common manifestations. Bone marrow suppression, immune mediated clearance and spontaneous aggregation of platelets to virus infected endothelium may be responsible for such thrombocytopenia.

The severity of dengue fever is predicted by severe thrombo- 
cytopenia. In a study done by Mandal et al there was severe thrombocytopenia in $38 \%$ of patients. We have found only 21 patients $(8.7 \%)$ having severe thrombocytopenia $(<50000 /$ cu. $\mathrm{mm}$ ) suggestive of lesser severity and low mortality rate in our study.

Liver enzymes such as Aspartate Transaminase (AST) and Alanine Transaminase (ALT) was elevated in more than $45 \%$ of cases in our study. Similar results was seen in the studies by Laul et al. ${ }^{27}$ Jayadas et al. ${ }^{20}$ found elevated AST than ALT level in accordance to our study and this may be secondary to release of AST from the parts other than liver (heart and striated muscles). Deranged liver function in dengue infection can be a result of the direct attack of the virus on liver cells or the unregulated host immune response against the virus. Fulminant hepatic failure occurs because of acute severe hepatitis and massive necrosis of the liver, causing hepatic encephalopathy and even death. ${ }^{22}$

The most common peak season for dengue infection in this study was in the month of mid-August to last week of September. This kind of seasonal response was seen in research conducted by Gupta et al. and studies from tropical countries like India, China and Philippines ., These months are the post monsoon period in Nepal where mosquitoes have a favourable climate to breed and multiply thus serving as a vector for transmission of virus in humans. ${ }^{5}$

The most common type of serological test to be positive in this study was Dengue NS1 antigen test. NS1antigen test was positive in 201 patients-(84\%) followed by combined NS1 and IgM positivity in 23 patients (9.5\%). Similar result was shown in North Indian study and a study conducted by Chhotala et al. ${ }^{4}$ The higher NS1 positivity may be because many patients came to our hospital and got admitted within two or three days of fever when this particular test is specifically done aiding for early identification and prompt notification. There are also evidences that sensitivity of NS1 antigen test is higher in primary infection(>90\%) and even correlated with higher levels of viral load.

Dengue IgM antibody test was positive in only 11 patients (4.5\%) in our study. A study published in 2012 by Shah et al. 6 showed seropositivity of Dengue IgM cases to be $9 \%$ which was twice than our study.

\section{REFERENCES:}

1. IWilkerson RC, Linton $\mathrm{Y}-\mathrm{M}$, Fonseca DM, Schultz TR, Price DC, Strickman DA. Making Mosquito Taxonomy Useful: A Stable Classification of Tribe Aedini that Balances Utility with Current Knowledge of Evolutionary Relationships. PLoS One.2015;10(7):e0133602. [DOI]

2. Sujitha K, Dorasanamm M, Nagabhushana MV. The clinical and laboratory profile of dengue fever in a tertiary care hospital. Int J Adv Med. 2019;6(5):1-4. [DOI]

3. Kularatne SAM, Gawarammana IB, Kumarasiri PRV. Epidemiology, clinical features, laboratory investigations and early diagnosis of dengue fever in adults: a descriptive study in Sri lanka. Southeast Asian J Trop Med Public
The ultrasound findings in our study simulated with the study done by Laul et.al. ${ }^{27}$ Hepatomegaly and GB edema may be due to direct viral invasion of gall bladder and liver leading to protein rich plasma leak causing increase in severity. ${ }^{24}$

Out of 241 dengue cases admitted for a certain period in the ward there was only 1 death with a case fatality rate of $0.41 \%$ similar to the research conducted by Antony et al. and studies conducted in Jakarta and West Bengal. Our patient was 71 years old male, a known hypertensive, with history of fever for seven days and shortness of breath. He had thrombocytopenia, deranged liver and renal function tests with positive NS1 test and was admitted in medical intensive care unit (MICU) with the diagnosis of Dengue shock syndrome. He was monitored with central line, transfused with four pints of PRP, IV antibiotics, double ionotrope support and kept in Mechanical Ventilation. But despite all the treatment, patients died after 2 days in MICU. No mortality was recorded in a study conducted by Ratageri et al. and Khan et al. The overall mortality of dengue infection is low if treated appropriately and early, however the mortality due to DHF and DSS may be high.

It was a single centered study. Non availability of Dengue viral RNA study by RT-PCR (Reverse Transcriptase-Polymerase chain reaction) was the major limitation in our study. With this test we could have distinguished the various serotypes and the severity of different strains of virus.

\section{CONCLUSION}

Dengue, an arthropod borne viral disease poses a significant morbidity and a high financial burden. With each outbreak, the number of confirmed cases have increased significantly. In our analysis, Leucopenia, rather than thrombocytopenia was the most common laboratory finding. Furthermore, the study also showed cases from the hilly areas implying that dengue was not limited to terai regions only. Hence, there should be a proper surveillance of the infection, start an integrated vector control programme, make an awareness programme and emergency preparedness for this cyclical outbreak.

\section{CONFLICT OF INTEREST: None}

\section{FINANCIAL DISCLOSURE: None}

4. Chhotala YH, Suva CM. A study of clinical profile of dengue fever in a tertiary care hospital of Jamnagar, Gujarat, India. Int J Res Med Sci. 2016;4(10):4500-04. [DOI]

5. Gupta BP, Tuladhar R, Kurmi R, Manandhar KD. Dengue periodic outbreaks and epidemiological trends in Nepal. Ann Clin Microbiol Antimicrob. 2018;17(1):1-6. [DOI]

6. Shah Y, Khadka G, Gupta GP, Adhikari N, Poudel A, Pant KP, et al. Sero-diagnosis of dengue virus in different hospitals of Nepal. Int J Infect Microbiol. 2012;1(2):58-62. [DOI]

7. Adhikari N, Subedi D. The alarming outbreaks of dengue in Nepal. Tropi- 
cal Medicine and Health. 2020;48(5):1-3. [DOI]

8. Wai MNC. Revisiting the approach to dengue: The primary care perspective. The Singapore Family Physician. 2015;41(2): 65-73. [LINK]

9. World Health Organization, Dengue Hemorrhagic Fever: Diagnosis, Treatment and Control. Geneva: WHO; 1986.

10. Mehta SR, Bafna TA, Pokale AB. Demographic and clinical spectrum of dengue patients admitted in tertiary care hospital. Medical Journal of Dr.D.Y.Patil Vidyapeeth. 2018;11(2):128-31. [DOI]

11. Deshwal R, Qureshi MI, Singh R. Clinical and laboratory profile of dengue fever. J Assoc Physicians India. 2015;63(12):30-2. [PMID]

12. Gupta S, Bansal S. Epidemiology and seropositivity of dengue fever cases in a tertiary care hospital of NCR in 2013. East J Med Sci. 2017;2(1):4-7. [LINK]

13. Chitkara S, Chhina D, Gupta V, Maharjan R, Sharma D. Epidemiology of dengue fever among clinically suspected febrile patients at a tertiary care center in Punjab. J Microbiol Infect Dis. 2018;8(1): 43-8. [DOI]

14. Chrispal A, Boorugu H, Gopinath KG, et al. Acute undifferentiated febrile illness in adult hospitalized patients: the disease spectrum and diagnostic predictors - an experience from a tertiary care hospital in South India. Trop Doct. 2010;40(44): 230-34. [DOI]

15. Ittyachen AM, Ramachandran R. Study of acute febrile illness: a 10-year descriptive study and a proposed algorithm from a tertiary care referral hospital in rural Kerala in Southern India. Trop Doct. 2015; 45(2):114-17. [DOI]

16. Chatterjee N, Mukhopadhyay M, Ghosh S, Mondol M, Das C, Patar K. An observational study of dengue fever in a tertiary care hospital of Eastern India. J Assoc Physicians India. 2014;62(3):224-7. [PMID]

17. Kaplan JE, Eliason DA, Moore M, Sather GE, Schonberger LB, Coello LC, et al. Epidemiologic investigations of dengue infection in Mexico, 1980. Am J Epidemiol. 1983;117(3):335-43. [DOI]

18. Awasthi S, Singh VK, Kumar S, Kumar A, Dutta S. The changing clinical spectrum of dengue fever in the 2009 epidemic in North India: a tertiary teaching Hospital based study. Journal of Clinical and Diagnostic Research. 2012;6(6):999-02.

19. Nepal HP, Ansari S, Gyawali N, Gautam R, Paudel R, Shrestha S, et al. Detection of IgM against dengue virus in clinically suspected patients presenting at a tertiary care centre, Narayani Zone, Nepal. J Trop Dis. 2014;2(3):1-7. [DOI]

20. Jayadas TTP, Kumaran T, Arasaratnam V, Gajapathy K, Surendran SN. The clinical profile, hematological parameters and liver transaminases of dengue NS1 Ag positive patients admitted to Jaffna Teaching Hospital, Sri Lanka. BMC Res Notes. 2019;12:1-5. [DOI]

21. Pande PA, Jogdande AJ. Clinical profile and changes in laboratory parameters among dengue patients at tertiary care hospital:an observational study. Int J Community Med Public Health. 2019;6(5):2276-79. [DOI]

22. Rachel D, Rajamohanan, Philip AZ. A study of clinical profile of dengue fever in Kollam, Kerala, India. Dengue Bulletin. 2005; 29:197- 202. [LINK]

23. Karoli R, Fatima J, Siddiqi Z, Kazmi KI, Sultania AR. Clinical profile of dengue infection at a teaching hospital in North India. J Infect Develop Ctries. 2012;6(7):551-4. [DOI]
24. Singh N, Jhamb R, Agarwal SK, Gaiha M, Dewan R, Daga M, et al. The 2003 outbreak of dengue fever in Delhi, India. Southeast Asian J Trop Med Public Health. 2005; 36(5): 1174-78. [PMID]

25. Dhivya P, Monica A, Jayaramachandran S. Clinical profile of Dengue fever in an urban tertiary care hospital in South India. Int J of Adv Med. 2019;6(3):618-22. [DOI]

26. Kumar A, Rao CR, Pandit V, Shetty S, Bammigatti C, Samarasinghe CM, et al. Clinical manifestations and trend of dengue cases admitted in a tertiary care hospital,Udupi district, Karnataka. Indian J Community Medicine. 2010;35(3):386-90. [DOI]

27. Laul A, Laul P, Merugumala V, Pathak R, Miglani U, Saxena P. Clinical profiles of dengue Infection during an outbreak in Northern India. Journal of Tropical Medicine. 2016;16:1-7. [DOI]

28. Majeed Al, Avabratha KS, Gowda LR, Syeda S. Clinicohaematological profile of dengue in children: a hospital based study. Int J Contemp Pediatr. 2017;4(4):1340-44. [DOI]

29. Mandal SK, Ganguly J, Sil K, Chaterjee S, Chaterjee K, Sarkar P, Hazra S, et al. Clinical profiles of dengue fever in a teaching hospital of eastern India. Natl J Med Res. 2013;3(2):173-76. [LINK]

30. Gupta BP, Singh S, Kurmi R, Malla R, Sreekumar E, Manandhar KD. Reemergence of dengue virus serotype 2 strains in the 2013 outbreak in Nepal. Indian J Med Res. 2015;142 (1):1-6. [DOI]

31. Lai S, Huang Z, Zhou H, Anders KL, Perkins TA, Yin W, et al. The changing epidemiology of dengue in China, 1990-2014:a descriptive analysis of 25 years of nationwide surveillance data. BMC Med. 2015;13:100-104. [DOI]

32. Edillo FE, Halasa YA, Largo FM,Erasmo JNV, Amoin NB, Alera MTP, et al. Economic cost and burden of dengue in the Philippines. Am J Trop Med Hyg. 2015;92(2):360-66. [DOI]

33. Khan SA, Dutta P, Topno R, Soni M, Mahanta J. Dengue Outbreak in Hilly State of Arunachal Pradesh in Northeast India. The Scientific World Journal. 2014:1-6. [DOI]

34. Hang VT, Nguyet NM, Trung DT, Tricou V, Yoksan S, Dung NM, et al. Diagnostic accuracy of NS1 ELISA and lateral flow rapid test for dengue sensitivity, specificity and relationship to viraemia and antibody responses. PLoS NegI Trop Dis. 2009;3(1):e360. [DOI]

35. Antony J, Celine TM. A descriptive study on dengue fever reported in a Medical College Hospital. Sahel Medical Jornal.2014;17(3):83-6. [LINK]

36. Sungkars, Fadli S, Sukmaningsih A. Trend of Dengue Hemorrhagic fever in North Jakarta. Journal of the Indoonesian Medical Association. 2012 61(10): 394-99. [LINK]

37. Kanungo S, Amarasingh A, Sur D, Manna B, Chaterjee S, Sadhukan P, et al. Surveillance for dengue fever in eastern Kolkata, West Bengal, India: preliminary results. International meeting on emerging diseases and surveillance, Abstract presented at IMED Vienna, Austria. Feb 13-16, 2009. Abstract no: 18.037, p. 148

38. Ratageri VH, Shepur TA, Wari PK, et al. Clinical profile and outcome of dengue fever cases. Indian J Pediatr. 2005;72(8):705-06. [DOI]

39. Khan NA, Azhar El, Fiky SE, Madani HH, Abulijadial MA, Ashshi AM, et al. Clinical profile and outcome of hospitalized patients during first outbreak of dengue in Makkah, Saudi Arabia. Acta Trop. 2008;105(1):39-44. [DOI] 